\title{
Life-course approach to nutrition
}

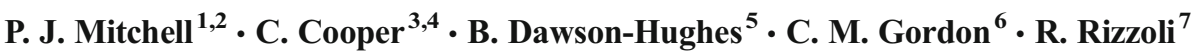

Received: 7 July 2015 / Accepted: 11 August 2015 / Published online: 28 September 2015

(C) International Osteoporosis Foundation and National Osteoporosis Foundation 2015

\section{Summary}

This narrative review summarizes the role that nutrition plays in the development and maintenance of a healthy skeleton throughout the life-course.

\begin{abstract}
Nutrition has a significant influence on bone health throughout the life cycle. This narrative review summarizes current knowledge and guidance pertaining to the development and maintenance of a healthy skeleton. The primary objectives proposed for good bone health at the various stages of life are the following:
\end{abstract}

- Children and adolescents: achieve genetic potential for peak bone mass

Paul Mitchell and Cyrus Cooper are joint first authors.

C. Cooper

cc@mrc.soton.ac.uk

1 Synthesis Medical NZ Ltd, Auckland, New Zealand

2 University of Notre Dame Australia, Sydney, Australia

3 NIHR Musculoskeletal Biomedical Research Unit, Nuffield Department of Orthopaedics, Rheumatology and Musculoskeletal Sciences, University of Oxford, Oxford, UK

4 MRC Lifecourse Epidemiology Unit, University of Southampton, Southampton General Hospital, Southampton, UK

5 Jean Mayer USDA Human Nutrition Research Center on Aging, Tufts University, Boston, MA, USA

6 Divisions of Adolescent Medicine and Endocrinology, Hasbro Children's Hospital, Alpert Medical School of Brown University, Providence, RI, USA

7 Division of Bone Diseases, Geneva University Hospitals and Faculty of Medicine, Geneva, Switzerland
- Adults: avoid premature bone loss and maintain a healthy skeleton

- Seniors: prevention and treatment of osteoporosis

Findings from cohort studies, randomized controlled trials, systematic reviews and meta-analyses, in addition to current dietary guidelines, are summarized with the intention of providing clear nutritional guidance for these populations and pregnant women.

Keywords Calcium $\cdot$ Life-course $\cdot$ Nutrition $\cdot$ Osteoporosis · Protein · Vitamin D

\section{Introduction}

The purpose of this narrative review is to summarize the latest evidence relating to the nutritional needs of mothers, children and adolescents, adults and seniors, in relation to developing and maintaining a healthy skeleton. Expectant mothers must be sufficiently well-nourished to support an infant's development in utero. The findings of mother-offspring cohort studies demonstrate the impact of maternal diet during pregnancy on bone health outcomes for children. An overview of current dietary guidelines for expectant mothers is provided. The primary objective relating to bone health during childhood and adolescence is achievement of an individual's genetic potential for peak bone mass. Inadequate calcium intake and vitamin D insufficiency are widely documented among women of child-bearing age, pregnant women, and children and adolescents. The relationship between fracture incidence in childhood and later life is considered. The third section of the review focuses on the role of nutrition in maintaining bone mass during the adult decades from the twenties until the sixties, with particular attention to calcium, vitamin D and 
protein. The final section summarizes the international guidance on the specific nutritional needs of seniors. In conclusion, the place of nutrition in a broader systematic approach to fragility fracture care and prevention is also considered.

\section{Maternal nutrition}

The early life environment has long-term consequences for musculoskeletal development, beginning in utero. The relationship between birth weight and bone mass in adulthood was the subject of a systematic review and meta-analysis published in 2011 [1]. A 1-kg increase in birth weight was associated with a $1.49-\mathrm{g}$ increase in lumbar spine bone mineral content (BMC) $(95 \%$ CI 0.77-2.21) and a 1.41-g increase in hip BMC (95\% CI 0.91-1.91). The primary studies used in the meta-analysis included adult men and women aged between 18 and 80 years across a range of settings. Thinness in childhood has been shown to be a risk factor for hip fracture in later life. Birth weight and length at birth were recorded, as well as height and weight throughout childhood for 6370 girls born in Helsinki between 1934 and 1944 [2]. The incidence of hip fracture in later life for this cohort was obtained from the National Finnish Hospital discharge register. Women who had been in the lowest quarter for change in Z-scores for body mass index (BMI) between 1 and 12 years of age had an 8.2-fold increase in hip fracture risk (95\% CI 1.9-35), as compared to those in the highest quarter $(P<0.001)$. Determination of the factors during pregnancy which may underpin these relationships has been conducted through studies of mother-offspring cohorts. To date, the following factors have been identified:

- Maternal body build [3, 4]

- Lifestyle [3, 4]

- Physical activity [3]

- Diet [5-10]

- Vitamin D status [11, 12]

\section{The role of maternal diet during pregnancy}

Maternal diet during pregnancy is the main determinant of foetal nutrition and has been shown to influence bone mass during childhood. Investigators from several countries have evaluated the impact of maternal diet on bone health outcomes for children, the findings of which are summarized in Table 1 $[5-10,13]$. Although the general pattern of maternal diet during gestation appears related to offspring bone development, with more healthy maternal diets associated with greater offspring bone mass [8], the gestational micronutrient that has been most strongly associated with offspring bone development is vitamin D.

\section{The role of maternal vitamin $D$}

Vitamin D insufficiency is common in pregnancy, particularly in pregnant women residing at northern latitudes. A motheroffspring cohort study from Southampton, UK, reported that $31 \%$ of mothers had insufficient $(11-20 \mathrm{ng} / \mathrm{mL})$ and $18 \%$ had deficient $(<11 \mathrm{ng} / \mathrm{mL})$ circulating concentrations of 25 hydroxyvitamin $\mathrm{D}[25(\mathrm{OH}) \mathrm{D}]$ during the late stage of pregnancy [11]. A longitudinal study of pregnant adolescents in the Northeastern USA reported that approximately half of the adolescents and their infants had serum $25(\mathrm{OH}) \mathrm{D}$ of $<20 \mathrm{ng} /$ $\mathrm{mL}$ at mid-gestation (26 weeks) [14]. Among a cohort of pregnant women from Ireland, considering all three trimesters collectively, 34.3-52.6\% were vitamin D insufficient (11$20 \mathrm{ng} / \mathrm{mL})$ and $14.3-23.7 \%$ were deficient $(<11 \mathrm{ng} / \mathrm{mL})$, respectively [15].

Investigators from Southampton found that lower concentrations of gestational $25(\mathrm{OH}) \mathrm{D}$ were associated with reduced whole body and lumbar spine BMC and bone mass density (BMD) in children at 9 years of age [11]. Another study from the same group reported a correlation between maternal vitamin D concentrations and neonatal bone mass [16].

US investigators also assessed the impact of maternal vitamin D status and calcium intake, and interactions between the two, on foetal skeletal growth in utero in pregnant adolescents [17]. Higher calcium intake $(\geq 1050 \mathrm{mg} /$ day $)$ was associated with significantly greater foetal femur and humerus Z-scores $(P<0.03)$. Notably, only $29.4 \%$ of adolescents met the estimated average requirement (EAR; $1100 \mathrm{mg}$ /day) for calcium, and $15.3 \%$ of adolescents met the recommended dietary allowance (RDA; $1300 \mathrm{mg} /$ day $)$. Foetal femur $(P=0.003)$ and foetal humerus length $\mathrm{Z}$-scores $(P=0.006)$ were significantly higher for vitamin D sufficient $[25(\mathrm{OH}) \mathrm{D}>20 \mathrm{ng} / \mathrm{mL}]$ pregnant adolescents as compared to vitamin D insufficient adolescents. Potential interactions between the effects of maternal $25(\mathrm{OH}) \mathrm{D}$ sufficiency and maternal calcium intake $\geq 1050 \mathrm{mg} /$ day on foetal bone length were modelled. Calcium intake was associated with foetal femur Z-scores and birth length only when maternal $25(\mathrm{OH}) \mathrm{D}$ was $<20 \mathrm{ng} / \mathrm{mL}(P<0.05)$. Similarly, maternal 25(OH)D was associated with foetal femur and humerus $Z$-scores only when maternal calcium intake was $<1050 \mathrm{mg} /$ day $(P<0.03)$. So, higher calcium intakes compensated for suboptimal vitamin $\mathrm{D}$ status and vice versa. It is not known if these results are transferable to the pregnant adult population.

Information obtained from the Danish Foetal Origins 1988 Cohort has enabled the exploration of potential associations between maternal vitamin D status and occurrence of fractures in offspring up to age 18 years [18]. Vitamin D status was available for $88 \%(n=850)$ of the pregnant women, and 294 


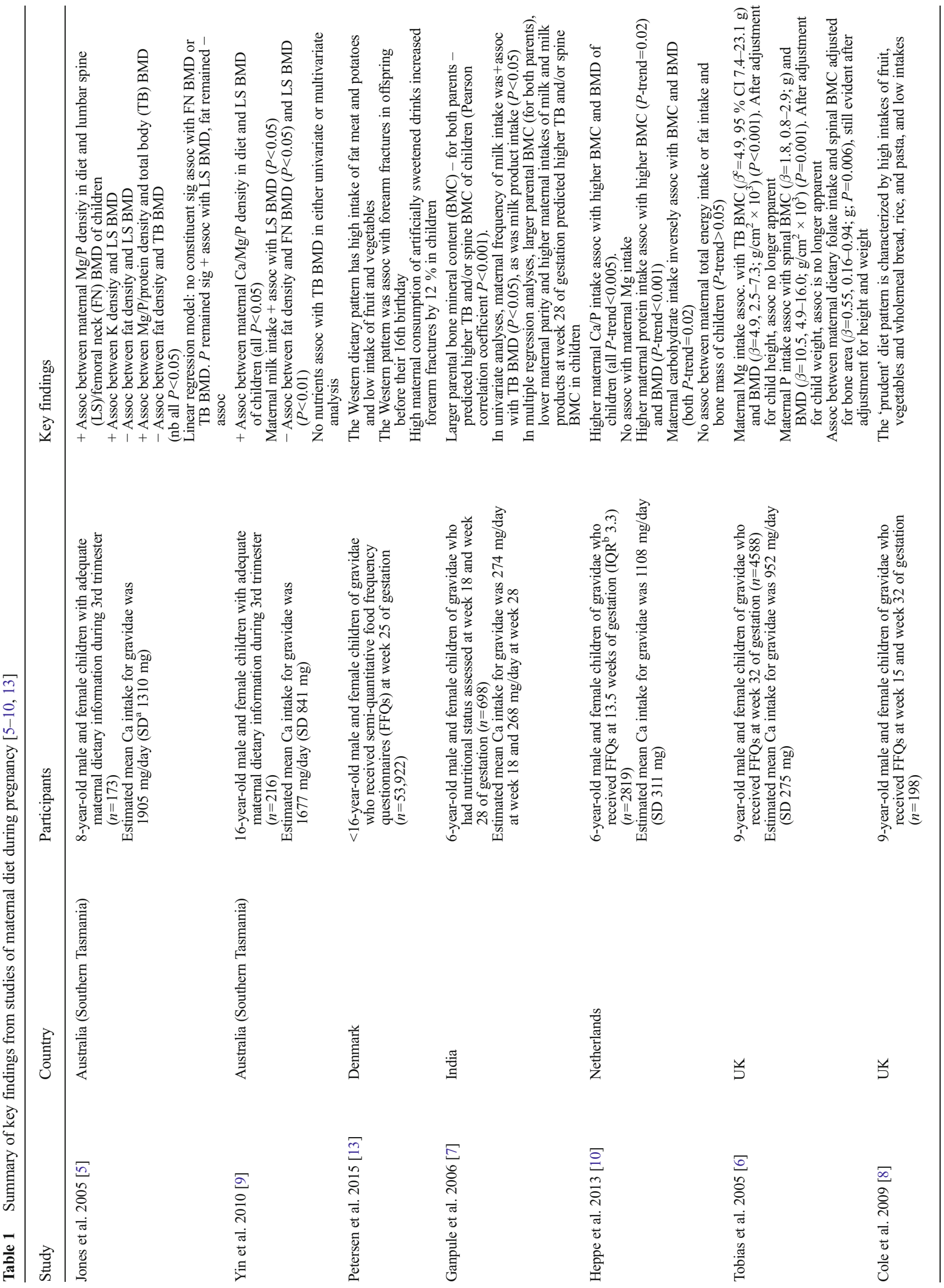


children had at least one fracture recorded on the Danish National Patient Register. No overall association was observed between maternal vitamin $\mathrm{D}$ status and first fracture in the children. However, a seasonal effect was evident. The hazard ratio for fractures among children whose mother had blood drawn in winter months, as compared to those who had blood drawn in summer months, was significantly higher (HR 1.75, $95 \%$ CI 1.11-2.74). Notably, adjustment for maternal vitamin $\mathrm{D}$ status strengthened this interaction. When considered as a continuous variable, a borderline significantly inverse relationship was apparent between $25(\mathrm{OH}) \mathrm{D}$ levels and offspring forearm fractures $(P=0.054)$.

The safety and effectiveness of vitamin D supplementation during pregnancy have been assessed in a single-centre, doubleblind, randomized clinical trial (RCT) of 494 women in South Carolina, USA [19]. Women with a singleton pregnancy at 12 16 weeks' gestation received 400, 2000 or 4000 IU of vitamin $\mathrm{D}_{3}$ per day until delivery $(n=350)$. Vitamin D supplementation of $4000 \mathrm{IU} /$ day was shown to be safe and the most effective dose to achieve sufficiency in all women. It should be noted that no functional outcome benefits were observed with supplementation. However, with regard to assessment of bone outcomes in offspring, to date, only one small-scale intervention study has considered the impact of vitamin D supplementation in pregnancy [20]. In order to address this gap in the evidence base, the UK Maternal Vitamin D Osteoporosis Study (MAVIDOS) will test whether offspring of mothers supplemented with vitamin D in pregnancy have higher bone mass at birth than those whose mothers were not supplemented [21]. This multicentre study randomized women in a double-blind design to either oral vitamin D supplement (1000 IU cholecalciferol/day, $n=477$ ) or placebo at 14 weeks gestation $(n=477)$. Infants will undergo dual-energy $\mathrm{x}-$ ray absorptiometry (DXA) assessments within the first 14 days after birth and at age 4 years. The trial has completed neonatal follow-up and results will be reported in full later in 2015.

\section{Interaction between genes and the environment in utero}

Fine-tuning of gene expression mediated through epigenetic processes enables an organism to make short-term adaptations to the prevailing environment for one or two generations [22]. These changes do not involve mutation of deoxyribonucleic acid (DNA). The primary molecular mechanisms involved are DNA methylation, chromatin histone modification and noncoding ribonucleic acids (RNA). Two studies have evaluated epigenetic influences on the developmental origins of osteoporosis:

- Endothelial nitric oxide synthase (eNOS) is important in bone metabolism, playing a mechanistic role in the function of osteocytes, osteoblasts and osteoclasts [23]. 
Investigators sought to relate the methylation status of the eNOS gene promoter in stored umbilical cord to bone size and mineral density in children aged 9 years. An association was apparent between methylation status at birth and bone size and density.

- Retinoid X receptor-alpha (RXRA) is an essential cofactor in the action of 1,25-dihydroxyvitamin D [24]. Methylation of the RXRA gene promoter in umbilical cord was inversely associated with percentage bone mineral content (\%BMC) and BMC corrected for body size at 4 years old.

In time, epigenetic studies may provide a basis for development of novel biomarkers to identify children who are at increased risk of poor bone health in later life.

\section{Dietary guidelines and the needs of expectant mothers}

Several guidelines have considered the dietary needs of expectant mothers which are of relevance to bone health [25-28].

In February 2015, the Dietary Guidelines Advisory Committee (DGAC) published an Advisory Report for the Secretary of Health and Human Services and the Secretary of Agriculture [25]. The DGAC found that several nutrients are under-consumed relative to the EAR or the adequate intake (AI) levels set by the Institute of Medicine (IOM) [29]. Calcium, vitamin D, fibre and potassium were classified as 'nutrients of public health concern' because of well-documented links to adverse health outcomes. Furthermore, the US Food and Drug Administration (FDA) designated calcium and vitamin D as nutrients of 'public health significance' in its recent review of evidence in publishing a Proposed Rule on the Nutrition Facts label [30]. Notably, among pregnant women, $90 \%$ had intakes below the EAR for vitamin D and $24 \%$ had intakes below the EAR for calcium. The DGAC note specifically that calcium is an under-consumed nutrient of public health concern among pregnant women. Guidelines from the American Academy of Pediatrics (AAP) [26] and the Endocrine Society [27] have proposed strategies to achieve the RDA of vitamin D which include the following:

- Consumption of fortified foods

- Broadening the range of dairy products that are fortified

- In some cases, the use of a vitamin D supplement or multivitamin including vitamin D

Strategies to improve calcium intake include increased consumption of dairy or fortified products that are important sources of calcium.
In the UK, the National Health Service (NHS) recommends expectant mothers take a supplement containing 400 IU vitamin $\mathrm{D}$ each day throughout pregnancy and during breastfeeding [31]. The recommendation highlights that women who choose to take a multivitamin supplement to obtain vitamin D should not use any supplements containing vitamin A (retinol), as too much could be harmful to the infant. In 2014, the National Institute for Health and Clinical Excellence (NICE) published Public Health Guidance 56 on increasing vitamin D supplement use among at risk groups, including pregnant women [28]. The guidance notes that the main natural source is from the action of sunlight on skin. However, from mid-October to the beginning of April in the UK, there is no ambient ultraviolet sunlight of the appropriate wavelength for skin synthesis of vitamin D, resulting in a significant minority of adults and children having low levels [32].

\section{Childhood and adolescence}

Achieving an individual's genetic potential for peak bone mass is the primary objective relating to bone health during childhood and adolescence. A theoretical analysis published in 2003 considered the relative influences of peak BMD, agerelated bone loss and menopause on the development of osteoporosis in women [33]. Variation of peak BMD had by far the greatest influence on the average age at which a T-score of less than 2.5 standard deviations below the young adult mean was projected to be reached. Development of osteoporosis would occur 13 years later if the peak BMD was increased by $10 \%$. By comparison, a $10 \%$ change in the age at menopause or the rate of non-menopausal bone loss would delay the onset of osteoporosis by just 2 years.

The Bone Mineral Density in Childhood Study (BMDCS) investigators hypothesized that BMD would 'track' along a particular trajectory throughout childhood and adolescence [34]. BMDCS is a multicentre longitudinal study of 1554 boys and girls in the USA who were evaluated annually for up to 6 years. Approximately one third $(n=533)$ of the participants completed the full 6 years of follow-up and were sexually and skeletally mature at final follow-up. Children were categorized according to their baseline DXA Z-scores as low $(<-1.5)$, intermediate $(-1.5$ to 1.5$)$ or high $(>1.5)$. Almost all participants who had initial $Z$-scores less than -1.5 remained below the mean of normal $(Z=0)$, and the majority were below -1.0 at final follow-up. Similarly, participants who had initial Z-scores above 1.5 remained above the mean. Tracking was stronger for girls as compared to boys. Given the practical difficulty of conducting a longitudinal study that would follow individuals from childhood to old age, the investigators concluded that observation of relatively low BMD prior to 
attainment of peak bone mass could identify individuals at higher risk of developing osteoporosis in later life.

\section{Gender differences in skeletal development}

At birth, there is no difference between the genders in terms of bone mass of either the axial or appendicular skeleton. Adolescence is a pivotal period in skeletal development during which approximately half of bone mass is accumulated [35]. A quarter of adult skeletal calcium is acquired during the 2-year period when peak height velocity occurs [36]. The age of peak calcium accretion is 14 and 12.5 years for boys and girls, respectively. Accrual of bone mass during childhood and adolescence is controlled by sex steroids and the growth hormone/insulin-like growth factor I (IGFI) axis of the endocrine system [37]. Androgens have been shown to increase cortical bone size, while oestrogens reduce it. Accordingly, during puberty, boys develop larger bones than girls which have a thicker cortex. Consequently, boys generally have higher peak bone mass than girls, as illustrated in Fig. 1.

\section{Nutrition}

While genetics contributes up to $80 \%$ of the variance of BMD observed within the population [38], nutrition, exercise and lifestyle, body weight and composition, and hormonal status all affect bone mass accrual in children and adolescents [26]. Specifically, calcium, vitamin D and protein are the most important nutrients for bone health during the first two decades.

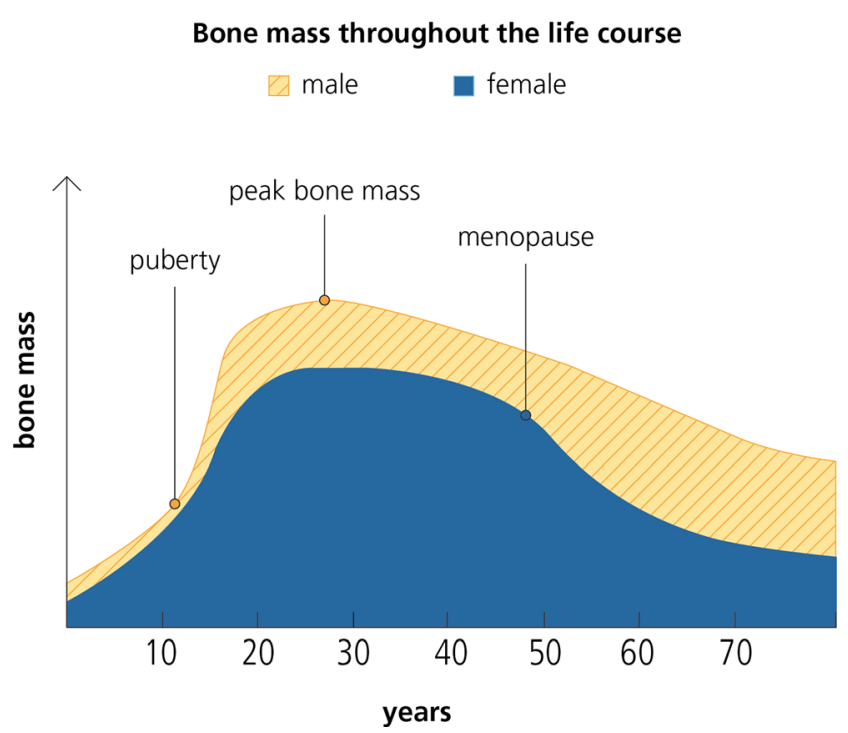

Fig. 1 Bone mass throughout the life cycle

\section{Calcium}

Inadequate calcium intake is a worldwide problem which has been reported among women of child-bearing age [39, 40], pregnant women [25], children and adolescents [41].

Approximately $300 \mathrm{mg}$ of calcium is required each day to produce adequate breast milk [42]. Studies intended to assess the relationship between maternal calcium intake and calcium content in breast milk have reported equivocal findings [43-45]. This suggests that changes in maternal calcium metabolism, intestinal calcium absorption efficiency and renal calcium handling may collectively result in adequate provision of calcium to the breastfed infant, even when maternal calcium intake is very low $[43,44]$.

Analysis of the long-term impact of duration of breastfeeding (BF) on bone health has been conducted in Finland [46]. A prospective cohort study followed children from birth until 32 years of age, when BMD was measured. The cohort was divided into three equal-size groups according to the total duration of BF: short ( $\leq 3$ months), intermediate and prolonged ( $\geq 7$ months) BF groups. Notably, males in the short $\mathrm{BF}$ group had, on average, $4.7 \%$ higher whole body BMD than males in the prolonged group. No differences were observed in women. A potential explanation for the difference in males was that formula milk and commercial cow milk/cow milk dilutions had significantly higher calcium and phosphate contents. Calcium content was 1.4 times higher in the formula, 3.1 times higher in the cow milk dilution, and 4.4 times higher in the commercial cow milk, as compared with breast milk. Phosphorus content was 2.6, 6.3 and 12 times higher, respectively, when compared with breast milk. The authors found the lack of a difference between the groups in women surprising, but offered no explanation regarding why this should be so.

From the second year of life onwards, milk and dairy products are the source of up to $80 \%$ of dietary calcium intake for children. Accordingly, it is of concern that since the 1970s, a decline in milk consumption among children and adolescents has been reported in several developed countries [47], including France [48], Germany [49] and the USA [50]. So-called milk displacement, where carbonated beverages (sodas) are preferred to milk, is increasing worldwide and is associated with decreased consumption of milk, calcium and other nutrients [51].

The dietary reference intakes (DRI) for calcium recommended by IOM in the USA are shown by age range for children in Table 2 [29]. Preschool children in the UK have been reported to have suboptimal calcium intake relative to the UK Department of Health reference nutrient intake [RNI, a comparable measure to recommended dietary allowances (RDAs) used by the IOM] [52]. Less than $15 \%$ of adolescent girls in the USA consume the IOM RDA, with average intake being $876 \mathrm{mg} /$ day [40].

The impact of calcium supplementation on bone density in healthy children has been evaluated in a meta- 
Table 2 US Institute of Medicine calcium dietary reference intakes for infants and children [29]

\begin{tabular}{lll}
\hline Age & Calcium RDA (mg/day) & Calcium UL (mg/day) \\
\hline 0-6 months & $200^{\mathrm{b}}$ & 1000 \\
6-12 months & $260^{\mathrm{b}}$ & 1500 \\
1-3 years & 700 & 2500 \\
4-8 years & 1000 & 2500 \\
9-13 years & 1300 & 3000 \\
14-18 years & 1300 & 3000 \\
\hline
\end{tabular}

${ }^{\mathrm{a}}$ The upper limit $(U L)$ highlights a level above which there is risk of adverse events

${ }^{\mathrm{b}}$ Because RDAs have not been established for infants, the adequate intake (AI) value is shown. AI is a value that meets the needs of most children

analysis of randomized controlled trials [53]. Calcium supplementation had no effect on BMD at the femoral neck or lumbar spine, although a small effect on total body $\mathrm{BMC}$ was reported.

\section{Vitamin D}

Vitamin D insufficiency has been reported throughout the world and is prevalent among women of child-bearing age, pregnant women, children and adolescents [41]. The International Osteoporosis Foundation (IOF) has mapped data relating to children and adolescents throughout the world as shown in Fig. 2a [54].

Comprehensive review articles have described in detail both the physiology of vitamin D [55-57], including its role in calcium and phosphate homeostasis, and the role of vitamin D in skeletal health in infants and children [58]. The authors of the latter review concluded that there was insufficient evidence to support the notion that low 25(OH)D was associated with increased fracture risk during childhood. Furthermore, the relationship between 25(OH)D status and BMD was not clear, with the caveat that supplementation in children with the lowest levels of $25(\mathrm{OH}) \mathrm{D}$ might improve BMD.

The DRI for vitamin D recommended by the IOM are shown by age range for children in Table 3 [29]. Dietary sources of vitamin D are limited to fatty fish, egg yolk, nuts and some types of fungi, which do not feature significantly in the diets of children and adolescents. A recent pan-European study concluded that adolescent consumers of ready-to-eat cereals (RTECs) had favourable micronutrient intake, including vitamin $\mathrm{D}$, as compared to nonconsumers of RTECs [59].

Guidance from Australia [60], UK [61] and USA [26] recommends vitamin D supplementation for infants and young children. A recent expert position statement reviewed evidence of skeletal and extra-skeletal effects of vitamin D in childhood and adolescence, and provided recommendations on vitamin D supplementation in children and adolescents [62].

\section{Protein}

Dietary protein plays two important roles with respect to bone health in children and adolescents:

- Provides a source of amino acids to build the bone matrix

- Stimulates IGF-I which is important for bone formation

The genetic potential for peak bone mass can be affected by variation in protein intake considered to be within the normal range (i.e., $0.8-1.5 \mathrm{~g} / \mathrm{kg}$ body weight/day) [63]. As milk provides a high-quality source of protein, investigators from Sheffield, UK, evaluated the effect of milk supplementation on total body bone mineral acquisition in adolescent girls [64]. At baseline, both groups consumed an average of $150 \mathrm{~mL}$ of milk/day, which increased by an average of $300 \mathrm{~mL} /$ day in the milk group throughout the 18-month trial. Significantly higher serum concentrations of IGF-I were observed in the milk group as compared to the control group ( 35 vs $25 \%, P=$ 0.02 ) and higher total body BMD (9.6 vs $8.5 \%, P=0.017$; repeated measures analysis of variance) and BMC (27.0 vs $24.1 \%, P=0.009$ ). Additionally, diets low in protein can result in reduced calcium retention [65]. The DRI for protein recommended by the IOM are shown by age range for children in Table 4 [29].

\section{Dietary pattern analysis}

The value of investigating the role of individual dietary components on bone health has been challenged, on account of the potential for interactions between the various components of the diet to confound findings of single-nutrient-focused studies. To address this question, US investigators conducted a cross-sectional analysis of healthy premenopausal women aged 18-30 years to determine whether existing indices of overall diet quality were associated with bone density in young women nearing peak bone mass [66]. The indices used were the Alternate Healthy Eating Index (AHEI) and the Recommended Food Score (RFS), which are based on the 1995 Dietary Guidelines for Americans and the food guide pyramid developed by US Department of Agriculture [65]. No associations were observed between bone density and diet quality score, continuous dietary variables or individual components of the AHEI. This study suggested that a new dietary pattern index was required to better predict measures of bone mass. 
Fig. 2 a IOF map of vitamin D status in children and adolescents [54]. b IOF map of vitamin D status in adults [54] a IOF map of vitamin D status in children and adolescents

Vitamin D level

$>75 \mathrm{nmol} / \mathrm{L} \quad 50-74 \mathrm{nmol} / \mathrm{L} \quad 25-49 \mathrm{nmol} / \mathrm{L} \square<25 \mathrm{nmol} / \mathrm{L}$

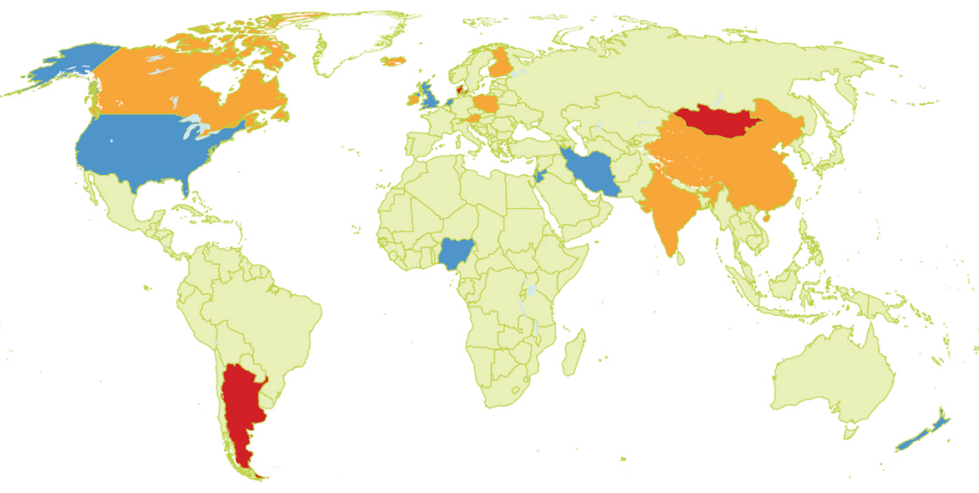

b IOF map of vitamin D status in adults

Vitamin D level

$>75 \mathrm{nmol} / \mathrm{L} \square 50-74 \mathrm{nmol} / \mathrm{L} \quad 25-49 \mathrm{nmol} / \mathrm{L} \square<25 \mathrm{nmol} / \mathrm{L}$

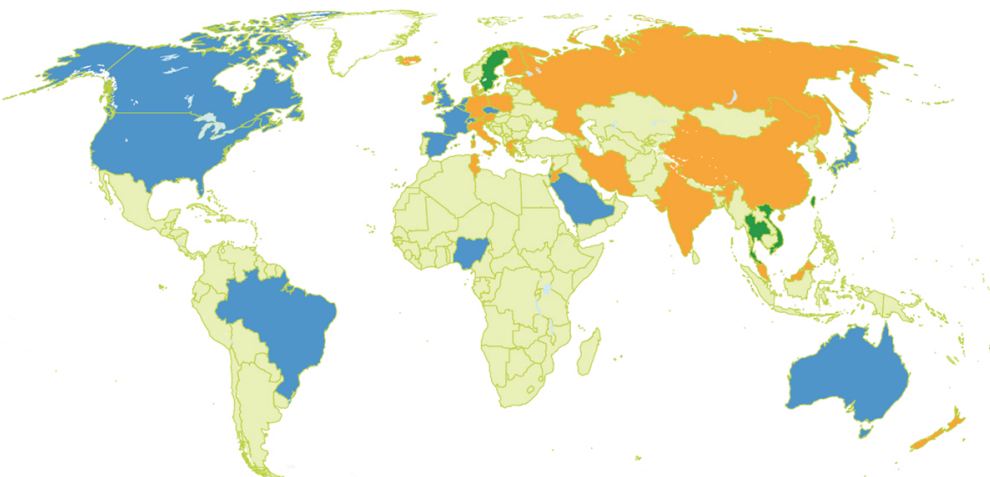

Table 3 US Institute of Medicine vitamin D dietary reference intakes for infants and children [29]

\begin{tabular}{lll}
\hline Age & Vitamin D RDA (IU/day) & Vitamin D UL (IU/day) $^{\mathrm{a}}$ \\
\hline 0-6 months & $400^{\mathrm{b}}$ & 1000 \\
6-12 months & $400^{\mathrm{b}}$ & 1500 \\
1-3 years & 600 & 2500 \\
4-8 years & 600 & 3000 \\
9-13 years & 600 & 4000 \\
14-18 years & 600 & 4000 \\
\hline
\end{tabular}

${ }^{\text {a }}$ The upper limit $(U L)$ highlights a level above which there is risk of adverse events

${ }^{\mathrm{b}}$ Because recommended dietary allowances (RDAs) have not been established for infants, the adequate intake (AI) value is shown. AI is a value that meets the needs of most children
More recently, principal component analysis (PCA) was applied to the Generation R Study cohort of children [67]. Three major dietary patterns were extracted, which explained $30 \%$ of the variation in dietary intake:

- Potatoes, rice and vegetables: characterized by high loadings for potatoes, pasta and rice, vegetables, meat and meat products, fish and shellfish, oils and condiments and sauces

- Refined grains and confectionery: characterized by high intakes of refined grains, solid fats, confectionery, snack bar products and savoury snacks, and sugar-containing beverages

- Dairy and whole grains: characterized by high loadings for whole grains, dairy and cheese, and eggs, and a negative loading for breast milk and infant formula 
Table 4 US Institute of Medicine protein dietary reference intakes for infants and children [29]

\begin{tabular}{lll}
\hline Age & Protein RDA (g/day) & Protein AMDR (g/day) \\
\hline $0-6$ months & $9.1^{\mathrm{b}}$ & $\mathrm{ND}^{\mathrm{c}}$ \\
7-12 months & 11 & $\mathrm{ND}^{\mathrm{c}}$ \\
1-3 years & 13 & $5-20$ \\
4-8 years & 19 & $10-30$ \\
9-13 years & 34 & $10-30$ \\
14-18 years (males) & 52 & $10-30$ \\
14-18 years (females) & 46 & $10-30$
\end{tabular}

${ }^{a}$ The acceptable macronutrient distribution range (AMDR) is the range of intake for a particular energy source that is associated with reduced risk of chronic disease while providing intakes of essential nutrients. If an individual consumed in excess of the AMDR, there is a potential of increasing the risk of chronic diseases and insufficient intakes of essential nutrients

${ }^{\mathrm{b}}$ Because RDAs have not been established for infants aged 0-6 months, $\mathrm{AI}$ value is shown. $\mathrm{AI}$ is a value that meets the needs of most children

${ }^{\mathrm{c}}$ Not determinable (ND) due to lack of data of adverse effects in this age group and concern with regard to lack of ability to handle excess amounts. Source of intake should be from food only to prevent high levels of intake

Children who demonstrated higher adherence to the 'dairy and whole grains' pattern, according to food frequency questionnaires completed by their mothers, had higher total body BMD and area-adjusted BMC (aBMC) at 6 years of age. Children in the highest quartile of the dairy and whole grains pattern had higher BMD (difference $3.98 \mathrm{mg} / \mathrm{cm}^{2}, 95 \%$ CI 0.36-7.61) and aBMC (difference 4.96 g, $95 \%$ CI 1.27-8.64) than children in the lowest quartile. Notably, the association between the dairy and whole grains' pattern and bone outcomes was only observed in children who did not receive vitamin D supplementation.

\section{Fracture trends in childhood and later life}

Studies in boys [68] and girls [69] have shown an association between the incidence of fractures during childhood and adolescence, and markers for low peak bone mass. Another study from the Mayo Clinic suggested that fractures in children and adolescents have two distinct causes [70]:

1. Fractures resulting from mild trauma which suggest underlying skeletal fragility

2. Fractures resulting from moderate trauma when bone strength is normal

Distal forearm fractures (DFFs) are the most common fracture type suffered by young people. The Mayo investigators subsequently sought to establish whether a DFF in childhood or adolescence identifies a subpopulation predisposed to develop suboptimal peak bone mass, which tracks into adulthood [70]. A group of 75 women and 75 men aged 2040 years, who had sustained a DFF before age 18 years, were compared to 150 sex-matched controls with no history of fracture. Bone strength was examined by high-resolution peripheral quantitative computed tomography (HR-pQCT) to determine failure load by micro-finite element $(\mu \mathrm{FE})$ analysis, as well as cortical and trabecular bone parameters at the distal radius and tibia. Those individuals who sustained a DFF in childhood as a result of mild trauma had significant reductions in failure load compared to fracture-free controls. However, individuals who sustained fractures as a result of moderate trauma had similar values to controls. Furthermore, those with mild trauma fractures had significantly diminished distal radius cortical area and significant bone density at the radius, hip and total body regions compared to controls (all $p<0.05$ ). These findings suggest that children and adolescents who suffer mild trauma DFFs should be candidates for lifestyle interventions to improve bone health.

\section{Maintaining bone mass in adulthood}

This section of the review focuses on the role of nutrition in the years between achievement of peak bone mass and the onset of age-related bone loss (i.e., from the twenties until the sixties for most individuals). The primary bone health objective during this phase of life is avoidance of premature bone loss and maintenance of a healthy skeleton. Throughout life, bone is in a constant state of turnover described as the bone remodelling cycle. During this 30-40-year period, bone mass remains comparatively high in both sexes until the onset of menopause in women and the beginning of the eighth decade in men. As for younger individuals, a well-balanced diet rich in calcium, vitamin $\mathrm{D}$ and protein, with adequate amounts of certain other micronutrients, will fulfil the nutritional requirements of the adult skeleton.

\section{Calcium}

Inadequate dietary intake of calcium has been reported among adults in Asia, Europe, Oceania and North America [41].

Calcium is the most abundant mineral in the human body and plays several important physiological roles relating to nerve and muscle function. The molecular mechanisms which are triggered by low-calcium diets have been reviewed in detail elsewhere [71]. In short, the concentration of calcium in blood is maintained within very narrow limits $(2.2-2.5 \mathrm{mmol} /$ L), which is sensed by the parafollicular cells of the thyroid gland and calcium-sensing receptors on the parathyroid glands. When calcium levels are high, the thyroid gland secretes calcitonin which lowers calcium levels through inhibition of three processes: calcium absorption in the intestines, 
osteoclast activity and renal tubular reabsorption of calcium. Calcitonin also stimulates osteoblast activity. When calcium levels are low, calcitonin secretion is inhibited and parathyroid hormone $(\mathrm{PTH})$ is secreted. $\mathrm{PTH}$, which has a short half-life (about $4 \mathrm{~min}$ ), serves to increase calcium levels through effects on the bone, the kidney and the intestines. PTH binds to osteoblasts, resulting in increased expression of receptor activator of nuclear factor kappa-B ligand (RANKL) and inhibited expression of osteoprotegerin (OPG). OPG can bind to RANKL, serving to inhibit RANKL from interacting with its receptor, RANK. This is important because when RANKL and RANK bind, osteoclast precursors are stimulated to fuse to form new osteoclasts, resulting in increased bone resorption and release of skeletal calcium into the blood. PTH enhances active reabsorption of calcium and magnesium from distal tubules and the thick ascending limb. PTH also enhances the absorption of calcium in the intestine by increasing the production of activated vitamin D.

IOF has developed a calcium calculator which is available online at http://www.iofbonehealth.org/calciumcalculator or as an App available from the iTunes App Store and through Google Play. The calculator quantifies calcium intake from a broad range of food types. Among individuals who are lactose intolerant, some mineral waters and tap waters can provide a significant source of dietary calcium. In North America, calcium concentration of tap water varies from 1 to $135 \mathrm{mg} / \mathrm{L}$ [72]. In Spain, the average calcium concentration of public drinking waters is $39 \mathrm{mg} / \mathrm{L}$, ranging from 0.4 to $160 \mathrm{mg} / \mathrm{L}$ [73]. The average calcium concentration of Spanish mineral waters is $40 \mathrm{mg} / \mathrm{L}$, ranging from 0.6 to $610 \mathrm{mg} / \mathrm{L}$.

Recommendations on dietary calcium intake for adults from several leading organizations are consistent:

- Australia: National Health and Medical Research Council RDI for calcium for adults aged $19-50$ years is $1000 \mathrm{mg} /$ day [74]

- USA: IOM dietary reference intake for calcium for adults aged 19-50 years is $1000 \mathrm{mg} /$ day [29]

- World Health Organization/Food and Agriculture Organization of the United Nations: WHO/FAO dietary reference Intake for calcium for adults aged $25-50$ years is $1000 \mathrm{mg} /$ day [75]

In light of the widespread suboptimal levels of dietary calcium intake, under what circumstances should healthy individuals take calcium supplements? An ongoing debate in the literature has sought to establish the risk-benefit ratio of calcium supplementation with respect to beneficial effects on bone health as compared to adverse impacts on the cardiovascular system [76]. Supplements should be used only as needed to bring total calcium intake to the recommended level.

\section{Vitamin D}

Vitamin D insufficiency is prevalent among adults throughout the world [41, 54], as illustrated in the IOF map in Fig. 2b.

Adults at elevated risk of having inadequate levels of vitamin D include the following individuals:

- Living at higher latitudes with minimal exposure to sunlight

- Who are obese

- With a darker skin tone

- Who cannot expose their skin to the sun for medical or cultural reasons

- With diseases that reduce uptake of vitamin D from the intestine

- Who are institutionalized

Vitamin D exerts direct and indirect effects on bone health. Calcium absorption has been shown to be higher in individuals with higher mean serum 25(OH)D [77]. Individuals pre-treated with vitamin $\mathrm{D}$, such that their average mean serum $25(\mathrm{OH}) \mathrm{D}$ concentration was $34.7 \mathrm{ng} / \mathrm{mL}$, had $65 \%$ higher absorption of calcium compared to control subjects with average mean serum 25(OH)D concentrations of $20.1 \mathrm{ng} / \mathrm{mL}$. Vitamin D plays an important role in the mineralization of bone [78]. Examination of iliac crest biopsies found pathologic mineralization defects in patients with a serum $25(\mathrm{OH}) \mathrm{D}$ below $20 \mathrm{ng} / \mathrm{mL}$. Serum concentrations of PTH have been shown to be lower in individuals with relatively higher concentrations of serum $25(\mathrm{OH}) \mathrm{D}$, so reducing PTH-induced bone loss [79]. Among men and women aged 20 years and over in the USA, 25(OH)D status has been shown to be the dominant predictor of BMD as compared to calcium intake [80]. As $25(\mathrm{OH}) \mathrm{D}$ concentrations increase (from $<20$ to $20-30$ to $>30 \mathrm{ng} / \mathrm{mL}$ ), BMD increased significantly in a stepwise fashion (value for trend women, $P<0.0001$; men, $P=0.0001$ ). In terms of indirect effects on bone health, vitamin $\mathrm{D}$ has been shown to stimulate muscle tissue [81] and thus reduce fall risk [82].

The primary source of vitamin $\mathrm{D}$ is endogenous synthesis in the epidermis, where 7-dehydrocholesterol is photochemically converted to pre-vitamin $\mathrm{D}_{3}$ in response to ultraviolet $\mathrm{B}$ exposure, which subsequently spontaneously isomerizes to cholecalciferol (vitamin $\mathrm{D}_{3}$ ). The IOM RDA for vitamin D for adults aged 19-70 years (as cholecalciferol) is $600 \mathrm{IU} /$ day [29]. Dietary sources of vitamin D are limited to fatty fish (e.g., mackerel, salmon, sardines and tuna), egg yolk, some nuts and some types of fungi (e.g., shiitake mushrooms).

Population screening for vitamin D deficiency is not recommended. However, measurement of serum $25(\mathrm{OH}) \mathrm{D}$ in high-risk individuals enables assessment of response to supplementation and the need for dose adjustment. In 2013, the US Preventive Services Task Force (USPSTF) evaluated the effects of vitamin D supplementation, with or without 
calcium, on bone health outcomes in community-dwelling adults [83]. The USPSTF reached the following conclusions:

- The current evidence is insufficient to assess the balance of the benefits and harms of combined vitamin D and calcium supplementation for the primary prevention of fractures in premenopausal women or in men.

- The current evidence is insufficient to assess the balance of the benefits and harms of daily supplementation with greater than $400 \mathrm{IU}$ of vitamin $\mathrm{D}_{3}$ and greater than $1000 \mathrm{mg}$ of calcium for the primary prevention of fractures in non-institutionalized postmenopausal women.

\section{Protein and other micronutrients}

The relationship between dietary protein and bone health was first subjected to systematic review and meta-analysis in 2009 [84]. A small positive association was shown between protein intake and BMD and BMC. However, there was no association evident for a reduction in hip fracture risk. Vitamin $\mathrm{K}$ is required to make osteocalcin functional, which is the most abundant non-collagenous protein in bone. While epidemiological studies suggest that diets high in vitamin $\mathrm{K}$ are associated with lower risk of hip fracture in older people [85], supplementation with vitamin $\mathrm{K}_{1}$ or $\mathrm{K}_{2}$ in RCTs did not result in increases in BMD at major sites [86]. $\mathrm{B}$ vitamins have the potential to ameliorate adverse effects on bone health mediated by hyperhomocysteinemia, because homocysteine levels can rise when blood levels of vitamin $\mathrm{B}_{6}$, vitamin $\mathrm{B}_{12}$ and folic acid are low. Observational studies have reported an association between high homocysteine levels and low BMD [87] and elevated hip fracture risk in older people [88]. A recent randomized controlled trial has evaluated the effect of vitamin $\mathrm{B}_{12}(500 \mu \mathrm{g})$ and folic acid $(400 \mu \mathrm{g})$ supplementation on BMD and quantitative ultrasound parameters in older people with hyperhomocysteinemia [89]. After 2 years of supplementation, neither significant differences were observed between the treatment and placebo groups for BMD at the lumbar spine or femoral neck, nor for calcaneal broadband ultrasound attenuation (BUA) or calcaneal speed of sound. However, a small positive effect of the intervention on BUA was observed in the subgroup of individuals who were aged over 80 years and were compliant with the treatment. Compliance was defined as having taken at least $80 \%$ of the supplement tablets during the intervention period. Further studies are required to definitively evaluate the role of supplementation with B vitamins on prevention of osteoporosis. The role of vitamin A in bone health remains controversial [90]. Population-based studies have reported an association between high dietary intake of preformed vitamin A and greater risk of osteoporosis and hip fracture. However, intake of vitamin A precursor carotenoids has been linked to improved bone health. In terms of minerals, magnesium stimulates proliferation of osteoclasts. However, magnesium deficiency is rare in well-nourished populations. Zinc plays a role in renewal and mineralization of bone tissue, and deficiency can be common in community-dwelling older people [91].

\section{Acid-base balance of the diet}

The prevalence of chronic kidney disease and end-stage renal disease among older people is increasing [92]. Diets which have low intakes of fruit and vegetables, and high intakes of cereal grains and protein, are increasingly common. Taken together, these two phenomena contribute to a low-grade, progressive metabolic acidosis among a growing number of older people. An acid environment has been shown to impair osteoblast function [93], accelerate bone resorption by enhancing osteoclast survival, adhesion, and migration [94], and also exert a direct negative physico-chemical effect on the bone [95].

In 2011, a systematic review and meta-analysis sought to evaluate causal relationships between dietary acid load and osteoporosis [96]. The investigators concluded that no association was evident and, conversely, that there is no evidence that an alkaline diet is protective of bone health. A limitation of this meta-analysis was that the primary studies were not weighted for sample size and that young and older subjects were included. More recent studies have sought to evaluate daily consumption of a dose of alkali on measures of bone health.

In 2013, a randomized, double-blind, placebo-controlled study compared measurements of areal BMD (aBMD) at the lumbar spine by DXA, volumetric density (vBMD) and microarchitectural parameters measured by HR-pQCT, and fracture risk assessment by FRAX ${ }^{\circledR}$ for healthy older adults [97]. Men and women aged over 65 years received $60 \mathrm{mmol}$ of potassium citrate or placebo daily for 24 months. All participants were provided with calcium $(500 \mathrm{mg})$ and vitamin $\mathrm{D}_{3}$ (400 IU) supplements. At 24 months, aBMD at the lumbar spine was significantly higher for the potassium citrate group compared to placebo $(1.7 \pm 1.5 \%, 95 \%$ CI 1.0-2.3, $P<0.001)$. Similarly, trabecular densities measured by HR-pQCT were higher for the intervention group at the nondominant tibia $(1.3 \pm 1.3 \%, 95 \%$ CI $0.7-1.9, P<0.001)$ and the nondominant radius $(2.0 \pm 2.0 \%, 95 \% \mathrm{CI} 1.4-2.7, P<0.001)$. In terms of microarchitectural parameters, significant increases were observed for trabecular bone volume/tissue volume, trabecular thickness and trabecular number for the intervention group. Potassium citrate supplementation was also associated with diminished FRAX ${ }^{\circledR}$ score in both sexes.

A second study published in 2013 described a randomized, double-blind, placebo-controlled study which compared 
measurements of bone turnover markers, net acid excretion and calcium metabolism for older men and women assigned to potassium citrate $60 \mathrm{mmol} / \mathrm{day}, 90 \mathrm{mmol} / \mathrm{day}$, or placebo daily [98]. At 6 months, dietary acid was completely neutralized in the two treatment groups. Furthermore, urinary excretion of calcium was significantly reduced in both treatment groups compared with placebo $(P<0.01,60 \mathrm{mmol} /$ day $[-46$ $\pm 15.9 \mathrm{mg} /$ day $]$ and $90 \mathrm{mmol} /$ day $[-59 \pm 31.6 \mathrm{mg} /$ day $])$. Net calcium balance was significantly improved for the higher dose group compared to placebo $(142 \pm 80 \mathrm{mg}$ /day on $90 \mathrm{mmol} /$ day vs $-80 \pm 54 \mathrm{mg} /$ day on placebo; $P=0.02$ ). Also, serum C-telopeptides decreased significantly in both potassium citrate groups compared to placebo, while bone-specific alkaline phosphatase did not change. In 2015, a dose-finding study evaluated the effect of potassium bicarbonate supplementation on bone turnover, calcium excretion and nitrogen excretion [99]. Daily doses of $1 \mathrm{mmol} / \mathrm{kg}$ (median dose $81 \mathrm{mmol} /$ day) and $1.5 \mathrm{mmol} / \mathrm{kg}$ (median dose $122 \mathrm{mmol} /$ day) of potassium bicarbonate were compared to placebo. For the primary outcome of change in 24-h urinary Ntelopeptides (NTX), a statistically significant reduction was observed for the low-dose group $(P=0.012)$. Both treatment groups had lower urinary calcium excretion, while no effect was observed on urinary nitrogen excretion for either dose group. The authors of both studies identify the need for long-term trials to assess the effect of supplementation with alkali on BMD and fracture risk.

\section{Lifestyle factors which can affect bone health}

The impact of alcohol on fracture risk has been assessed by analysis of a population of almost 17,000 men and women who participated in cohort studies from Australia, Canada and The Netherlands [100]. Alcohol intakes of 2 units or less per day were not associated with increased fracture risk. Consumption of alcohol above this threshold was associated with an increased risk of any fracture [risk ratio $(\mathrm{RR})=1.23 ; 95 \%$ CI 1.06-1.43], any fracture considered to be due to osteoporosis by the investigator $(\mathrm{RR}=1.38 ; 95 \% \mathrm{CI} 1.16-1.65)$, or hip fracture $(\mathrm{RR}=1.68 ; 95 \% \mathrm{CI} 1.19-2.36)$. Notably, the effect is over and above that which can be explained by variations in BMD.

The impact of smoking on fracture risk has been assessed by analysis of a population of more than 59,000 men and women who participated in ten prospective cohort studies from Australia, Europe, Japan and North America [101]. Current smoking was associated with increased fracture risk, as was a history of smoking. When adjusted for BMD, the RR for any fracture for current smokers compared to nonsmokers was 1.13. Smokers also had an increased risk, after adjustment for BMD, for any osteoporotic fracture $(\mathrm{RR}=1.13 ; 95 \% \mathrm{CI}$ $1.00-1.28)$ and for hip fracture $(\mathrm{RR}=1.60 ; 95 \%$ CI $1.27-$
2.02). Less than a quarter of the risk of hip fracture related to smoking was attributable to low BMD.

Other lifestyle factors which have been associated with adverse effects on bone health include high consumption of caffeinated beverages and having a very low or high BMI.

\section{Nutritional needs of seniors}

Malnutrition is very common among seniors and highly prevalent in the hospital, residential care and primary-care settings [102]. Causes of malnutrition in the elderly include proteinenergy malnutrition (PEM, i.e., starvation, cachexia and sarcopenia). Cachexia has been defined as 'a complex metabolic syndrome associated with underlying illness and characterized by loss of muscle with or without loss of fat mass' [103]. In 2010, the European Working Group on Sarcopenia in Older People (EWGSOP) developed a practical clinical definition and consensus diagnostic criteria for age-related sarcopenia, which is characterized by both low muscle mass and low muscle function (i.e., strength or performance) [104]. As for younger individuals, calcium, vitamin $\mathrm{D}$ and protein play an important role in maintaining bone health in older people. The dietary reference intakes for calcium, vitamin D and protein recommended by the IOM are shown for older people and the elderly in Table 5 [29].

\section{Calcium}

Calcium intake by seniors varies considerably throughout the world [41]. In Europe, intakes in Austria, Belgium, Denmark, France, Ireland and Poland are considerably lower than the IOM RDA shown in Table 5 [29], while intakes in Germany, the UK and The Netherlands are much closer to the RDA. In the USA, the 2015 DGAC Advisory Report described a mixed picture [25]. The majority of men (71\%) and women (81\%) aged over 70 years do not consume the EAR for calcium based on their consumption of food and beverages. When calcium supplements were taken into account the situation improved, with $55 \%$ of men and $49 \%$ of women below the EAR. At the other extreme, about $20 \%$ of women and $15 \%$ of men aged over 50 years consumed more calcium than the tolerable upper limit of intake (UL, $2000 \mathrm{mg} /$ day).

As discussed previously, calcium metabolism is regulated by intestinal absorption, renal reabsorption and bone turnover. Seniors have decreased intestinal absorption of calcium, which can be exacerbated by low vitamin D status, and decreased renal retention. The DRI for calcium recommended by the IOM are shown by age range for older people in Table 5 [29]. A consensus statement from the European Society for Clinical and Economic Aspects of Osteoporosis and Osteoarthritis (ESCEO) on musculoskeletal health in postmenopausal 
Table 5 US Institute of Medicine calcium, vitamin D and protein dietary reference intakes for older people and the elderly [29]

\begin{tabular}{lllll}
\hline Age & Gender & Calcium RDA (mg/day) & Vitamin D RDA (IU/day) & Protein RDA (g/day) \\
\hline $51-70$ years & Female & 1200 & 600 & 46 \\
& Male & 1000 & 800 & 56 \\
\multirow{5}{*}{70 years } & Female & 1200 & 600 & 46 \\
& Male & 1200 & 800 & 56 \\
\hline
\end{tabular}

women recommended a daily intake of $1000 \mathrm{mg}$ of calcium for women aged over 50 years [105].

In 2014, Dutch investigators sought to quantify calcium intake from calcium-dense dairy products for a cohort of 1526 female and 372 male fracture patients aged over 50 years [106]. Median calcium intake from dairy was $790 \mathrm{mg} /$ day, which was increased by $450 \mathrm{mg}$ when basic nutrition was taken into account. Compared to Dutch guidelines for calcium intake (adults $\leq 70$ years $1100 \mathrm{mg} /$ day and $>70$ years $1200 \mathrm{mg} /$ day), $60.5 \%$ of women and $59.1 \%$ of men achieved the recommended intake.

\section{Vitamin D}

Vitamin D insufficiency is highly prevalent among seniors throughout the world, whether insufficiency is defined as $<30$ or $<20 \mathrm{ng} / \mathrm{mL}$. Based on a definition of $<30 \mathrm{ng} / \mathrm{mL}$, an IOF position paper reported rates of insufficiency among postmenopausal women in Japan and South Korea, Malaysia and Thailand, and the USA as 90, 50 and $75 \%$, respectively [107]. The dietary reference intakes for vitamin $\mathrm{D}$ recommended by the IOM are shown for older people and the elderly in Table 5 [29]. It should be noted that these recommendations apply to the general population of older people.

Meta-analyses have been conducted to identify the optimal levels of vitamin $\mathrm{D}$ with regard to reduction of falls and fracture risk. With respect to falls, a mean serum level of $25(\mathrm{OH}) \mathrm{D}$ of at least $24 \mathrm{ng} / \mathrm{mL}$ is needed for optimal falls risk reduction [82]. With respect to fractures, the mean serum levels of $25(\mathrm{OH}) \mathrm{D}$ associated with reduced risk of non-vertebral fracture and hip fractures were 26.4 and $29.6 \mathrm{ng} / \mathrm{mL}$, respectively [108].

Several learned societies have developed guidance specifically focused on care of patients with or at increased risk for osteoporosis. These generally recommend higher intakes or 25(OH)D levels than the IOM:

- IOF: a target level of $25(\mathrm{OH}) \mathrm{D}$ for older individuals of $30 \mathrm{ng} / \mathrm{mL}$ [107]. The EAR for older adults to achieve a serum $25(\mathrm{OH}) \mathrm{D}$ level of $30 \mathrm{ng} / \mathrm{mL}$ is $800-1000 \mathrm{IU} /$ day.

- Endocrine Society: Adults aged 50-70 years and over 70 years require at least 600 and $800 \mathrm{IU} /$ day of vitamin D, respectively, [27]. However, to raise the blood level of
$25(\mathrm{OH}) \mathrm{D}$ above $30 \mathrm{ng} / \mathrm{mL}$ may require at least 1500 $2000 \mathrm{IU} /$ day of supplemental vitamin D.

- ESCEO: In postmenopausal women, vitamin D intake of $800 \mathrm{IU} /$ day is needed to maintain serum $25(\mathrm{OH}) \mathrm{D}$ levels greater than $20 \mathrm{ng} / \mathrm{mL}$ [105].

\section{Protein}

In 2012, the European Union Geriatric Medicine Society (EUGMS), in cooperation with other scientific organizations, established an International Study Group (the PROT-AGE Study Group) to review dietary protein needs with ageing. In 2013, the PROT-AGE Study Group published a position paper which provided the following key recommendations [109]:

- To maintain physical function, older people need more dietary protein than do younger people; older people should consume an average daily intake at least in the range of $1-1.2 \mathrm{~g} / \mathrm{kg}$ body weight/day.

- Most older adults who have an acute or chronic disease need even more dietary protein (i.e., $1.2-1.5 \mathrm{~g} / \mathrm{kg}$ body weight/day); people with severe illness or injury or with marked malnutrition may need as much as $2.0 \mathrm{~g} / \mathrm{kg}$ body weight/day.

- Older people with severe kidney disease who are not on dialysis (i.e., estimated glomerular filtration rate (GFR) $<30 \mathrm{~mL}$ per min per $1.73 \mathrm{~m}^{2}$ ) are an exception to the high-protein rule; these individuals need to limit protein intake.

- Protein quality, timing of intake and amino acid supplementation may be considered so as to achieve the greatest benefits from protein intake, but further studies are needed to make explicit recommendations.

- In combination with increased protein intake, exercise is recommended at individualized levels that are safe and tolerated.

The position paper also comments specifically on the subject of protein requirements for hip fracture patients and people living with osteoporosis. Supplementary protein or higher dietary intake of protein by older people who have been hospitalized with hip fracture has been shown to improve bone 
density [84, 110], reduce the risk of complications [111-113] and reduce rehabilitation time [110]. Among older people living with osteoporosis, higher BMD has been reported when protein intake was at levels higher than $0.8 \mathrm{~g} / \mathrm{kg}$ body weight/ day or was $24 \%$ of total energy intake [84, 114-116].

In 2013, the IOF Nutrition Working Group published a position paper on the impact of nutrition on muscle mass, strength and performance in older adults [117]. As protein plays an important role in muscle health, an intake of 1$1.2 \mathrm{~g} / \mathrm{kg}$ body weight/day was recommended.

\section{Treatment of osteoporosis}

While nutrition makes an important contribution to bone health among seniors, the majority of pharmacological treatments used for osteoporosis will be deployed among this segment of the population. A broad range of treatments have been licensed throughout the world during the last three decades. These treatments are available in a wide range of dosing options, including daily, weekly or monthly oral preparations and daily, quarterly, six-monthly or annual injections. Fracture reduction at the hip, vertebrae and other skeletal sites has been reported in multiple RCTs. A summary of the anti-fracture efficacy of these treatments, which was presented in European guidance for the diagnosis and management of osteoporosis in postmenopausal women from ESCEO and the Committee of Scientific Advisors of IOF, is shown in Table 6 [118].

A major focus of efforts to improve prevention of fragility fractures caused by osteoporosis is to close the persistent and pervasive postfracture care gap. Individuals who have suffered a prior fragility fracture are at significantly increased risk of further fractures, so should undergo assessments for osteoporosis and falls risk, and receive interventions in accordance with the national guidelines [119]. The IOF Capture the Fracture $^{\circledR}$ Programme [120] and national initiatives in Australia [121], Canada [122], New Zealand [121], Singapore [123], UK [124] and USA [125] are promoting widespread implementation of the Fracture Liaison Service (FLS) model of care. In the absence of a systematic approach to the delivery of postfracture care, many audits conducted throughout the world report that less than $20 \%$ of fracture patients are initiated on osteoporosis treatments as a result of their presentation with a fracture [120]. FLS have been shown to close this care gap. IOF has developed clinical standards for FLS in the form of the Best Practice Framework (BPF) [126]. The BPF comprises of 13 standards which set an international benchmark for FLS. Each standard has three levels of achievement: level 1, level 2 or level 3. The BPF:

1. Defines the essential and aspirational building blocks that are necessary to implement a successful FLS
2. Serves as the measurement tool for IOF to award 'Capture the Fracture ${ }^{\circledR}$ Best Practice Recognition' in celebration of successful FLS worldwide

At the time of writing, $128 \mathrm{FLS}$ appear on IOF 'map of best practice' [120]:

- 68 that have been evaluated and recognized as either gold, silver or bronze

- 25 are currently under review

- 35 awaiting further data

\section{Disease and disorders that affect nutritional status}

Several diseases and disorders adversely affect nutritional status. The reader is referred to recent reviews on the impact on bone health and management approaches for individuals suffering anorexia nervosa [127], inflammatory bowel disease [128], coeliac disease [129] and lactose maldigestion and intolerance $[130,131]$.

\section{A life-course approach to nutrition and fracture prevention}

This review has considered the role of nutrition in developing and maintaining a healthy skeleton throughout the life-course.

The maternal diet is the primary source of foetal nutrition and has been shown to influence bone mass during childhood. In general, healthy maternal diets are associated with greater bone mass in the offspring. Vitamin D plays a particularly significant role, which renders observations of widespread insufficiency of this micronutrient among women of childbearing age and pregnant women a cause for concern. National guidance regarding supplementation of vitamin D during pregnancy, as advocated by the National Health Service in the UK, may be merited in many countries.

Childhood and adolescence are critical periods for skeletal development. Determined efforts must be made to ensure that all children achieve their genetic potential for peak bone mass. Milk and dairy products comprise the mainstay of calcium intake for children, yet a precipitous decline in milk consumption by children has been observed across the world during the last few decades. This issue is particularly acute among adolescent girls, serving to underpin the notion that osteoporosis is a paediatric disease with geriatric consequences. Furthermore, vitamin D insufficiency is widespread among children and adolescents, which has led to recommendations in several countries for vitamin D supplements to be given to infants and young children. Recent studies suggest that low BMD during the first two decades tracks into young adulthood and that 
Table 6 Anti-fracture efficacy of frequently used osteoporosis treatments [118]

\begin{tabular}{|c|c|c|c|c|}
\hline \multirow[t]{2}{*}{ Treatment } & \multicolumn{2}{|c|}{ Effect on vertebral fracture risk } & \multicolumn{2}{|c|}{ Effect on non-vertebral fracture risk } \\
\hline & Osteoporosis & Established osteoporosis $^{\mathrm{a}}$ & Osteoporosis & Established osteoporosis $^{\mathrm{a}}$ \\
\hline Alendronate & + & + & $\mathrm{n} / \mathrm{a}$ & + (including hip) \\
\hline Risedronate & + & + & $\mathrm{n} / \mathrm{a}$ & + (including hip) \\
\hline Ibandronate & $\mathrm{n} / \mathrm{a}$ & + & $\mathrm{n} / \mathrm{a}$ & $++^{\mathrm{b}}$ \\
\hline Zoledronic acid & + & + & $\mathrm{n} / \mathrm{a}$ & $+^{\mathrm{c}}$ \\
\hline HRT & + & + & + & + (including hip) \\
\hline Raloxifene & + & + & $\mathrm{n} / \mathrm{a}$ & N/A \\
\hline Teriparatide and PTH & $\mathrm{n} / \mathrm{a}$ & + & $\mathrm{n} / \mathrm{a}$ & $+^{\mathrm{d}}$ \\
\hline Strontium ranelate & + & + & + (including hip $^{\mathrm{b}}$ ) & + (including hip ${ }^{\mathrm{b}}$ ) \\
\hline Denosumab & + & $+^{\mathrm{c}}$ & + (including hip) & $+^{\mathrm{c}}$ \\
\hline
\end{tabular}

n/a no evidence available

${ }^{\mathrm{a}}$ Women with a prior vertebral fracture

${ }^{\mathrm{b}}$ In subsets of patients only (post hoc analysis)

${ }^{\mathrm{c}}$ Mixed group of patients with or without vertebral fractures

${ }^{\mathrm{d}}$ Shown for teriparatide only

those who suffer low trauma fractures as children and adolescents should be the focus of lifestyle interventions to improve bone health in the long term.

From the third decade to the beginning of the seventh decade of life, the primary goal relating to bone health is to maintain a healthy skeleton and avoid premature bone loss. Despite there being a clear consensus shared by leading organizations on optimal levels for dietary calcium intake, actual intakes are often considerably below those recommended by national guidelines. Similarly, IOF has mapped vitamin D status among adults, which demonstrates alarmingly high levels of insufficiency and deficiency in all regions of the world. Lifestyle factors such as excessive alcohol consumption, smoking, high intake of caffeinated beverages and a very

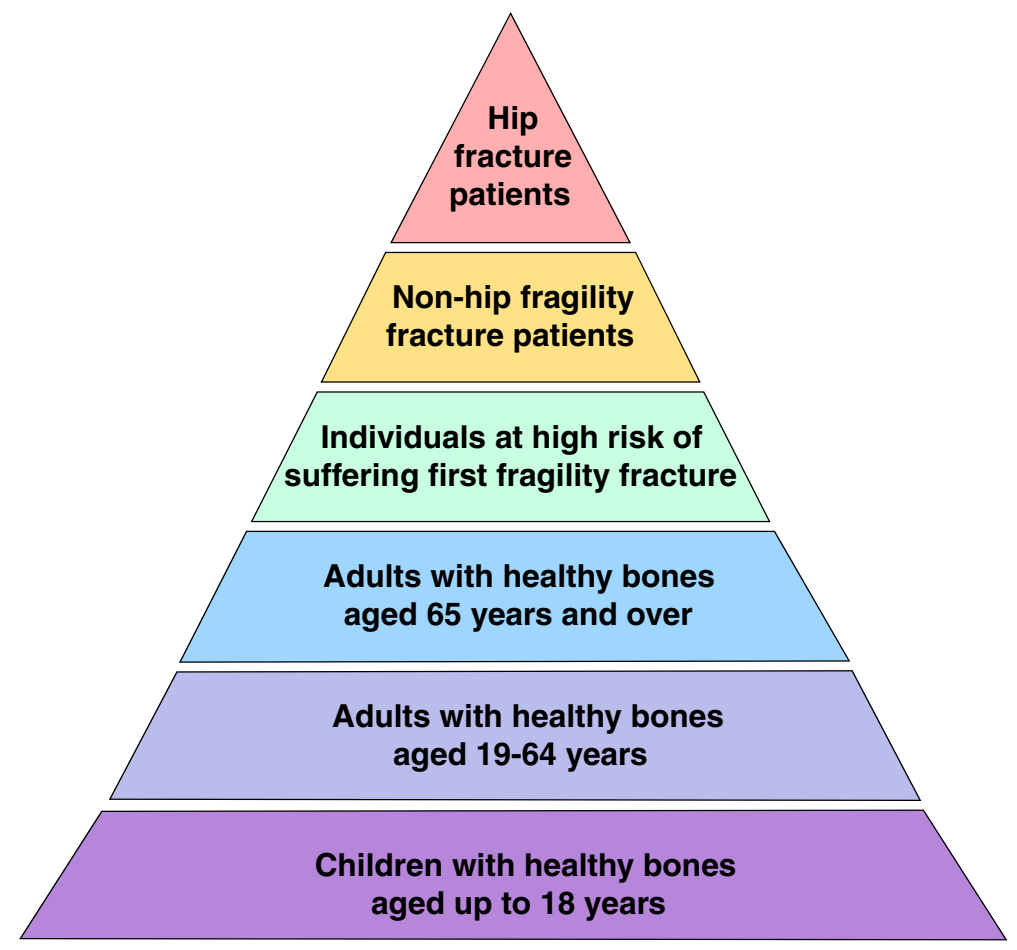

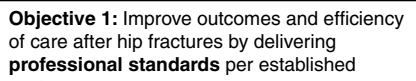

professional standards per established performance and quality measures

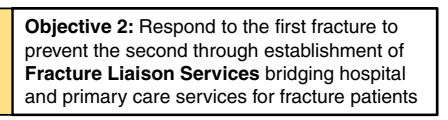

Objective 3: Health insurers or primary care providers to stratify risk for their patients using fracture risk assessment tools combined with bone density testing

Objective 4: Consistent delivery of public
health messages on preserving physical
activity, healthy lifestyles and reducing
environmental hazards

Objective 5: Consistent delivery of public health messages on maintaining adequate dietary intake of calcium, ensuring vitamin sufficiency and the benefits of regular exercise

Objective 6: Consistent delivery of public health messages on accrual of Peak Bone Mass through a well-balanced diet and regular exercise which promotes bone development

Fig. 3 A systematic approach to fragility fracture care and prevention for the USA [132] (reproduced with kind permission of the National Osteoporosis Foundation) 
high or low BMI also elevate fracture risk for substantial numbers of adults worldwide.

Fragility fractures most frequently occur among seniors. As for younger individuals, a significant proportion of seniors are not obtaining an adequate intake of calcium from their diet, and vitamin D insufficiency is highly prevalent among seniors throughout the world. Deficits in protein intake also adversely affect bone health among our older people, where malnutrition is common. Nutrition plays an important complementary role to pharmacotherapy for seniors who are at high fracture risk. A significant care gap exists for individuals who suffer fragility fractures of which major initiatives such as the IOF Capture the Fracture ${ }^{\circledR}$ Programme aim to eliminate.

A recent report from the National Osteoporosis Foundation (NOF) in the USA considered what progress has been made in the country since the publication of the Surgeon General's Report on Bone Health in 2004 [132]. A proposed strategy for the next decade is illustrated in Fig. 3. This graphic and the suggested programmes which relate to the six strata of the 'pyramid' provide a conceptual framework which integrates clinically led initiatives, such as hip fracture registries and FLS, with public health messaging:

- Programme 1: develop national hip fracture registries which will enable benchmarking of acute care against quality measures derived from national professional standards

- Programme 2: drive widespread adoption of FLS through publication of case studies, web-based and direct education, and national quality measures

- Programme 3: develop clinically effective and costeffective first fracture prevention programmes, and publish case studies, to drive systematic primary fracture prevention

- Programme 4: develop and implement public awareness campaigns on preserving physical activity, healthy lifestyles and reducing environmental hazards

- Programme 5: develop and implement public awareness campaigns on adequate dietary intake of calcium, ensuring vitamin D sufficiency and the benefits of regular exercise

- Programme 6: develop and implement public awareness campaigns for schools, students and parents on how to optimize peak bone mass accrual through diet and exercise

As the baby boomer generation ages, the incidence of fragility fractures, and hip fractures in particular, is set to escalate across the world, imposing an ever-increasing burden on already overstretched health systems and budgets. Nutrition plays a key role in the development and maintenance of a healthy skeleton and is an important component of a systematic approach to fragility fracture care and prevention, from before the cradle to the grave.
Acknowledgments The authors would like to thank Dr. Charanjit Jagait, IOF Communications Director, who is coordinating the 2015 IOF World Osteoporosis Day Campaign on the subject of nutrition through the life cycle, for her support in the preparation of this manuscript. We would also like to express our thanks to Mr. Gilberto Lontro, IOF Senior Graphic Designer, for his assistance in the preparation of the figures for this manuscript.

Conflicts of interest Paul Mitchell serves as a consultant to the International Osteoporosis Foundation and received remuneration for his contribution to this manuscript. René Rizzoli received fees for advisory boards or lectures for Amgen, Danone, Servier and Takeda.

\section{References}

1. Baird J, Kurshid MA, Kim M, Harvey N, Dennison E, Cooper C (2011) Does birthweight predict bone mass in adulthood? A systematic review and meta-analysis. Osteoporos Int 22:1323-1334

2. Javaid MK, Eriksson JG, Kajantie E, Forsen T, Osmond C, Barker DJ, Cooper C (2011) Growth in childhood predicts hip fracture risk in later life. Osteoporos Int 22:69-73

3. Godfrey K, Walker-Bone K, Robinson S, Taylor P, Shore S, Wheeler T, Cooper C (2001) Neonatal bone mass: influence of parental birthweight, maternal smoking, body composition, and activity during pregnancy. J Bone Miner Res 16:1694-1703

4. Harvey NC, Javaid MK, Arden NK et al (2010) Maternal predictors of neonatal bone size and geometry: the Southampton Women's Survey. J Dev Origins Health Dis 1:35-41

5. Jones G, Riley MD, Dwyer T (2000) Maternal diet during pregnancy is associated with bone mineral density in children: a longitudinal study. Eur J Clin Nutr 54:749-756

6. Tobias JH, Steer CD, Emmett PM, Tonkin RJ, Cooper C, Ness AR, ALSPAC Study Team (2005) Bone mass in childhood is related to maternal diet in pregnancy. Osteoporos Int 16:17311741

7. Ganpule A, Yajnik CS, Fall CH et al (2006) Bone mass in Indian children-relationships to maternal nutritional status and diet during pregnancy: the Pune Maternal Nutrition Study. J Clin Endocrinol Metab 91:2994-3001

8. Cole ZA, Gale CR, Javaid MK, Robinson SM, Law C, Boucher BJ, Crozier SR, Godfrey KM, Dennison EM, Cooper C (2009) Maternal dietary patterns during pregnancy and childhood bone mass: a longitudinal study. J Bone Miner Res 24:663-668

9. Yin J, Dwyer T, Riley M, Cochrane J, Jones G (2010) The association between maternal diet during pregnancy and bone mass of the children at age 16. Eur J Clin Nutr 64:131-137

10. Heppe DH, Medina-Gomez C, Hofman A, Franco OH, Rivadeneira F, Jaddoe VW (2013) Maternal first-trimester diet and childhood bone mass: the Generation R Study. Am J Clin Nutr 98:224-232

11. Javaid MK, Crozier SR, Harvey NC, Gale CR, Dennison EM, Boucher BJ, Arden NK, Godfrey KM, Cooper C, Princess Anne Hospital Study G (2006) Maternal vitamin D status during pregnancy and childhood bone mass at age 9 years: a longitudinal study. Lancet 367:36-43

12. Harvey NC, Holroyd C, Ntani G et al (2014) Vitamin D supplementation in pregnancy: a systematic review. Health Technol Assess 18:1-190

13. Petersen SB, Rasmussen MA, Olsen SF, Vestergaard P, Molgaard C, Halldorsson TI, Strom M (2015) Maternal dietary patterns during pregnancy in relation to offspring forearm fractures: prospective study from the Danish national birth cohort. Nutrients 7 : 2382-2400 
14. Young BE, McNanley TJ, Cooper EM, McIntyre AW, Witter F, Harris ZL, O’Brien KO (2012) Vitamin D insufficiency is prevalent and vitamin $\mathrm{D}$ is inversely associated with parathyroid hormone and calcitriol in pregnant adolescents. J Bone Miner Res 27: $177-186$

15. O'Riordan MN, Kiely M, Higgins JR, Cashman KD (2008) Prevalence of suboptimal vitamin D status during pregnancy. Ir Med J 101(240):242-243

16. Harvey NC, Javaid MK, Poole JR, Taylor P, Robinson SM, Inskip HM, Godfrey KM, Cooper C, Dennison EM, Southampton Women's Survey Study G (2008) Paternal skeletal size predicts intrauterine bone mineral accrual. J Clin Endocrinol Metab 93: 1676-1681

17. Young BE, McNanley TJ, Cooper EM, McIntyre AW, Witter F, Harris ZL, O'Brien KO (2012) Maternal vitamin D status and calcium intake interact to affect fetal skeletal growth in utero in pregnant adolescents. Am J Clin Nutr 95:1103-1112

18. Petersen SB, Olsen SF, Molgaard C, Granstrom C, Cohen A, Vestergaard P, Strom M (2014) Maternal vitamin D status and offspring bone fractures: prospective study over two decades in Aarhus City, Denmark. PLoS One 9, e114334

19. Hollis BW, Johnson D, Hulsey TC, Ebeling M, Wagner CL (2011) Vitamin D supplementation during pregnancy: double-blind, randomized clinical trial of safety and effectiveness. J Bone Miner Res 26:2341-2357

20. Congdon P, Horsman A, Kirby PA, Dibble J, Bashir T (1983) Mineral content of the forearms of babies born to Asian and white mothers. BMJ 286:1233-1235

21. Harvey NC, Javaid K, Bishop N, Kennedy S, Papageorghiou AT, Fraser R, Gandhi SV, Schoenmakers I, Prentice A, Cooper C (2012) MAVIDOS Maternal Vitamin D Osteoporosis Study: study protocol for a randomized controlled trial. The MAVIDOS Study Group. Trials 13:13

22. Jaenisch R, Bird A (2003) Epigenetic regulation of gene expression: how the genome integrates intrinsic and environmental signals. Nat Genet 33(Suppl):245-254

23. Harvey NC, Lillycrop KA, Garratt E et al (2012) Evaluation of methylation status of the eNOS promoter at birth in relation to childhood bone mineral content. Calcif Tissue Int 90:120-127

24. Harvey NC, Sheppard A, Godfrey KM et al (2014) Childhood bone mineral content is associated with methylation status of the RXRA promoter at birth. J Bone Miner Res 29:600-607

25. Dietary Guidelines Advisory Committee (2015) Scientific report of the 2015 Dietary Guidelines Advisory Committee: advisory report to the Secretary of Health and Human Services and the Secretary of Agriculture. US Department of Agriculture, Department of Health and Human Services-USA, Washington DC

26. Golden NH, Abrams SA, Committee on Nutrition (2014) Optimizing bone health in children and adolescents. Pediatrics 134:e1229-e1243

27. Holick MF, Binkley NC, Bischoff-Ferrari HA, Gordon CM, Hanley DA, Heaney RP, Murad MH, Weaver CM, Endocrine S (2011) Evaluation, treatment, and prevention of vitamin D deficiency: an Endocrine Society clinical practice guideline. J Clin Endocrinol Metab 96:1911-1930

28. National Institute for Health and Clinical Excellence (2014) Vitamin D: increasing supplement use among at-risk groups. NICE public health guidance 56. London

29. Institute of Medicine (2015) Dietary reference intakes tables and application. http://www.iom.edu/Activities/Nutrition/ SummaryDRIs/DRI-Tables.aspx Accessed 24 Feb 2015

30. U.S. Department of Health and Human Services (2014) Food labeling: revision of the nutrition and supplement facts labels; proposed rule. Federal Register [Internet]. Food and Drug Administration
31. NHS Choices (2015) Vitamins and nutrition in pregnancy: vitamin D in pregnancy. http://www.nhs.uk/conditions/pregnancy-andbaby/pages/vitamins-minerals-supplements-pregnant.aspx\#close Accessed 24 Feb 2015

32. Food Standards Agency (2007) Update on vitamin D: position statement by the Scientific Advisory Committee on Nutrition. Department of Health, Norwich

33. Hernandez CJ, Beaupre GS, Carter DR (2003) A theoretical analysis of the relative influences of peak BMD, age-related bone loss and menopause on the development of osteoporosis. Osteoporos Int 14:843-847

34. Wren TA, Kalkwarf HJ, Zemel BS, Lappe JM, Oberfield S, Shepherd JA, Winer KK, Gilsanz V, Bone Mineral Density in Childhood Study G (2014) Longitudinal tracking of dual-energy $\mathrm{X}$-ray absorptiometry bone measures over 6 years in children and adolescents: persistence of low bone mass to maturity. J Pediatr 164:1280-1285.e2

35. Parfitt AM (1997) Genetic effects on bone mass and turnoverrelevance to black/white differences. J Am Coll Nutr 16:325-333

36. Bailey DA, Martin AD, McKay HA, Whiting S, Mirwald R (2000) Calcium accretion in girls and boys during puberty: a longitudinal analysis. J Bone Miner Res 15:2245-2250

37. Russell M, Breggia A, Mendes N, Klibanski A, Misra M (2011) Growth hormone is positively associated with surrogate markers of bone turnover during puberty. Clin Endocrinol 75:482-488

38. Heaney RP, Abrams S, Dawson-Hughes B, Looker A, Marcus R, Matkovic V, Weaver C (2000) Peak bone mass. Osteoporos Int 11: 985-1009

39. Health Canada, Statistics Canada (2009) Canadian Community Health Survey, cycle 2.2, nutrition (2004)-nutrient intakes from food: provincial, regional and national data tables volumes 1,2 \& 3 disk. Health Canada Publications, Ottawa

40. Bailey RL, Dodd KW, Goldman JA, Gahche JJ, Dwyer JT, Moshfegh AJ, Sempos CT, Picciano MF (2010) Estimation of total usual calcium and vitamin D intakes in the United States. J Nutr 140:817-822

41. Peterlik M, Boonen S, Cross HS, Lamberg-Allardt C (2009) Vitamin D and calcium insufficiency-related chronic diseases: an emerging world-wide public health problem. Int J Environ Res Public Health 6:2585-2607

42. Kovacs CS (2001) Calcium and bone metabolism in pregnancy and lactation. J Clin Endocrinol Metab 86:2344-2348

43. Prentice A, Jarjou LM, Cole TJ, Stirling DM, Dibba B, Fairweather-Tait S (1995) Calcium requirements of lactating Gambian mothers: effects of a calcium supplement on breastmilk calcium concentration, maternal bone mineral content, and urinary calcium excretion. Am J Clin Nutr 62:58-67

44. Kalkwarf HJ, Specker BL, Bianchi DC, Ranz J, Ho M (1997) The effect of calcium supplementation on bone density during lactation and after weaning. N Engl J Med 337:523-528

45. Ortega RM, Martinez RM, Quintas ME, Lopez-Sobaler AM, Andres P (1998) Calcium levels in maternal milk: relationships with calcium intake during the third trimester of pregnancy. Br J Nutr 79:501-507

46. Pirila S, Taskinen M, Viljakainen H, Kajosaari M, Turanlahti M, Saarinen-Pihkala UM, Makitie O (2011) Infant milk feeding influences adult bone health: a prospective study from birth to 32 years. PLoS One 6, e19068

47. Dror DK, Allen LH (2014) Dairy product intake in children and adolescents in developed countries: trends, nutritional contribution, and a review of association with health outcomes. Nutr Rev $72: 68-81$

48. Lioret S, Dubuisson C, Dufour A, Touvier M, Calamassi-Tran G, Maire B, Volatier JL, Lafay L (2010) Trends in food intake in French children from 1999 to 2007: results from the INCA (etude 
Individuelle Nationale des Consommations Alimentaires) dietary surveys. Br J Nutr 103:585-601

49. Alexy U, Kersting M (2003) Time trends in the consumption of dairy foods in German children and adolescents. Eur J Clin Nutr 57:1331-1337

50. Nielsen SJ, Popkin BM (2004) Changes in beverage intake between 1977 and 2001. Am J Prev Med 27:205-210

51. Vartanian LR, Schwartz MB, Brownell KD (2007) Effects of soft drink consumption on nutrition and health: a systematic review and meta-analysis. Am J Public Health 97:667-675

52. Cribb VL, Northstone K, Hopkins D, Emmett PM (2014) Sources of vitamin $\mathrm{D}$ and calcium in the diets of preschool children in the UK and the theoretical effect of food fortification. J Hum Nutr Diet (in press)

53. Winzenberg T, Shaw K, Fryer J, Jones G (2006) Effects of calcium supplementation on bone density in healthy children: metaanalysis of randomised controlled trials. BMJ 333:775

54. International Osteoporosis Foundation (2015) Vitamin D status around the world in children, adolescents and adults. http:// www.iofbonehealth.org/facts-and-statistics/vitamin-d-studiesmap Accessed 10 Mar 2015

55. Shore RM, Chesney RW (2013) Rickets: part I. Pediatr Radiol 43: 140-151

56. Shore RM, Chesney RW (2013) Rickets: part II. Pediatr Radiol 43:152-172

57. Elder CJ, Bishop NJ (2014) Rickets. Lancet 383:1665-1676

58. Moon RJ, Harvey NC, Davies JH, Cooper C (2014) Vitamin D and skeletal health in infancy and childhood. Osteoporos Int 25: 2673-2684

59. Michels N, De Henauw S, Breidenassel C et al (2015) European adolescent ready-to-eat-cereal (RTEC) consumers have a healthier dietary intake and body composition compared with non-RTEC consumers. Eur J Nutr 54:653-664

60. Ebeling PR, Daly RM, Kerr DA, Kimlin MG (2013) An evidenceinformed strategy to prevent osteoporosis in Australia. Med J Aust 198:90-91

61. Davies SC, Jewell T, McBride M, Burns H (2012) Vitamin Dadvice on supplements for at risk: gateway reference 17193 . Welsh Government, Department of Health Social Services and Public Safety, The Scottish Government, Department of Health, Cardiff

62. Saggese G, Vierucci F, Boot AM, Czech-Kowalska J, Weber G, Camargo CA Jr, Mallet E, Fanos M, Shaw NJ, Holick MF (2015) Vitamin D in childhood and adolescence: an expert position statement. Eur J Pediatr 174:565-576

63. Rizzoli R (2008) Nutrition: its role in bone health. Best Pract Res Clin Endocrinol Metab 22:813-829

64. Cadogan J, Eastell R, Jones N, Barker ME (1997) Milk intake and bone mineral acquisition in adolescent girls: randomised, controlled intervention trial. BMJ 315:1255-1260

65. Kerstetter JE, O'Brien KO, Caseria DM, Wall DE, Insogna KL (2005) The impact of dietary protein on calcium absorption and kinetic measures of bone turnover in women. J Clin Endocrinol Metab 90:26-31

66. Zagarins SE, Ronnenberg AG, Gehlbach SH, Lin R, BertoneJohnson ER (2012) Are existing measures of overall diet quality associated with peak bone mass in young premenopausal women? J Hum Nutr Diet 25:172-179

67. van den Hooven EH, Heppe DH, Kiefte-de Jong JC, MedinaGomez C, Moll HA, Hofman A, Jaddoe VW, Rivadeneira F, Franco OH (2015) Infant dietary patterns and bone mass in childhood: the Generation R Study. Osteoporos Int 26:1595-1604

68. Chevalley T, Bonjour JP, van Rietbergen B, Ferrari S, Rizzoli R (2011) Fractures during childhood and adolescence in healthy boys: relation with bone mass, microstructure, and strength. J Clin Endocrinol Metab 96:3134-3142
69. Ferrari SL, Chevalley T, Bonjour JP, Rizzoli R (2006) Childhood fractures are associated with decreased bone mass gain during puberty: an early marker of persistent bone fragility? J Bone Miner Res 21:501-507

70. Farr JN, Amin S, Melton LJ 3rd, Kirmani S, McCready LK, Atkinson EJ, Muller R, Khosla S (2014) Bone strength and structural deficits in children and adolescents with a distal forearm fracture resulting from mild trauma. J Bone Miner Res 29:590 599

71. Centeno V, de Barboza GD, Marchionatti A, Rodriguez V, Tolosa de Talamoni N (2009) Molecular mechanisms triggered by lowcalcium diets. Nutr Res Rev 22:163-174

72. Morr S, Cuartas E, Alwattar B, Lane JM (2006) How much calcium is in your drinking water? A survey of calcium concentrations in bottled and tap water and their significance for medical treatment and drug administration. HSS J 2:130-135

73. Vitoria I, Maraver F, Ferreira-Pego C, Armijo F, Moreno Aznar L, Salas-Salvado J (2014) The calcium concentration of public drinking waters and bottled mineral waters in Spain and its contribution to satisfying nutritional needs. Nutr Hosp 30:188-199

74. National Health and Medical Research Council (2006) Nutrient reference values for Australia and New Zealand including recommended dietary intakes

75. Food and Agriculture Organization (2002) Human vitamin and mineral requirements: report of a joint $\mathrm{FAO} / \mathrm{WHO}$ Expert Consultation. Rome

76. Weaver CM (2014) Calcium supplementation: is protecting against osteoporosis counter to protecting against cardiovascular disease? Curr Osteoporos Rep 12:211-218

77. Heaney RP, Dowell MS, Hale CA, Bendich A (2003) Calcium absorption varies within the reference range for serum 25hydroxyvitamin D. J Am Coll Nutr 22:142-146

78. Priemel M, von Domarus C, Klatte TO et al (2010) Bone mineralization defects and vitamin D deficiency: histomorphometric analysis of iliac crest bone biopsies and circulating 25hydroxyvitamin D in 675 patients. J Bone Miner Res 25:305-312

79. Steingrimsdottir L, Gunnarsson O, Indridason OS, Franzson L, Sigurdsson G (2005) Relationship between serum parathyroid hormone levels, vitamin D sufficiency, and calcium intake. JAMA 294:2336-2341

80. Bischoff-Ferrari HA, Kiel DP, Dawson-Hughes B, Orav JE, Li R, Spiegelman D, Dietrich T, Willett WC (2009) Dietary calcium and serum 25-hydroxyvitamin D status in relation to BMD among U.S. adults. J Bone Miner Res 24:935-942

81. Ceglia L, da Silva Morais M, Park LK, Morris E, Harris SS, Bischoff-Ferrari HA, Fielding RA, Dawson-Hughes B (2010) Multi-step immunofluorescent analysis of vitamin $\mathrm{D}$ receptor loci and myosin heavy chain isoforms in human skeletal muscle. J Mol Histol 41:137-142

82. Bischoff-Ferrari HA, Dawson-Hughes B, Staehelin HB, Orav JE, Stuck AE, Theiler R, Wong JB, Egli A, Kiel DP, Henschkowski J (2009) Fall prevention with supplemental and active forms of vitamin D: a meta-analysis of randomised controlled trials. BMJ 339:b3692

83. Moyer VA, Force* USPST (2013) Vitamin D and calcium supplementation to prevent fractures in adults: U.S. Preventive Services Task Force recommendation statement. Ann Intern Med 158:691696

84. Darling AL, Millward DJ, Torgerson DJ, Hewitt CE, LanhamNew SA (2009) Dietary protein and bone health: a systematic review and meta-analysis. Am J Clin Nutr 90:1674-1692

85. Feskanich D, Weber P, Willett WC, Rockett H, Booth SL, Colditz GA (1999) Vitamin K intake and hip fractures in women: a prospective study. Am J Clin Nutr 69:74-79

86. Hamidi MS, Gajic-Veljanoski O, Cheung AM (2013) Vitamin K and bone health. J Clin Densitom 16:409-413 
87. Morris MS, Jacques PF, Selhub J (2005) Relation between homocysteine and B-vitamin status indicators and bone mineral density in older Americans. Bone 37:234-242

88. McLean RR, Jacques PF, Selhub J, Tucker KL, Samelson EJ, Broe KE, Hannan MT, Cupples LA, Kiel DP (2004) Homocysteine as a predictive factor for hip fracture in older persons. N Engl J Med 350:2042-2049

89. Enneman AW, Swart KM, van Wijngaarden JP et al (2015) Effect of vitamin B12 and folic acid supplementation on bone mineral density and quantitative ultrasound parameters in older people with an elevated plasma homocysteine level: B-PROOF, a randomized controlled trial. Calcif Tissue Int 96:401-409

90. Tanumihardjo SA (2013) Vitamin A and bone health: the balancing act. J Clin Densitom 16:414-419

91. Kvamme JM, Gronli O, Jacobsen BK, Florholmen J (2014) Risk of malnutrition and zinc deficiency in community-living elderly men and women: the Tromso Study. Public Health Nutr 1-7

92. Abdel-Rahman EM, Okusa MD (2014) Effects of aging on renal function and regenerative capacity. Nephron Clin Pract 127:15-20

93. Takeuchi S, Hirukawa K, Togari A (2013) Acidosis inhibits mineralization in human osteoblasts. Calcif Tissue Int 93:233-240

94. Ahn H, Kim JM, Lee K, Kim H, Jeong D (2012) Extracellular acidosis accelerates bone resorption by enhancing osteoclast survival, adhesion, and migration. Biochem Biophys Res Commun 418:144-148

95. Bushinsky DA (1996) Metabolic alkalosis decreases bone calcium efflux by suppressing osteoclasts and stimulating osteoblasts. Am J Physiol 271:F216-F222

96. Fenton TR, Tough SC, Lyon AW, Eliasziw M, Hanley DA (2011) Causal assessment of dietary acid load and bone disease: a systematic review \& meta-analysis applying Hill's epidemiologic criteria for causality. Nutr J 10:41

97. Jehle S, Hulter HN, Krapf R (2013) Effect of potassium citrate on bone density, microarchitecture, and fracture risk in healthy older adults without osteoporosis: a randomized controlled trial. J Clin Endocrinol Metab 98:207-217

98. Moseley KF, Weaver CM, Appel L, Sebastian A, Sellmeyer DE (2013) Potassium citrate supplementation results in sustained improvement in calcium balance in older men and women. J Bone Miner Res 28:497-504

99. Dawson-Hughes B, Harris SS, Palermo NJ, Gilhooly CH, Shea MK, Fielding RA, Ceglia L (2015) Potassium bicarbonate supplementation lowers bone turnover and calcium excretion in older men and women: a randomized dose-finding trial. J Bone Miner Res (in press)

100. Kanis JA, Johansson H, Johnell O, Oden A, De Laet C, Eisman JA, Pols H, Tenenhouse A (2005) Alcohol intake as a risk factor for fracture. Osteoporos Int 16:737-742

101. Kanis JA, Johnell O, Oden A et al (2005) Smoking and fracture risk: a meta-analysis. Osteoporos Int 16:155-162

102. Agarwal E, Miller M, Yaxley A, Isenring E (2013) Malnutrition in the elderly: a narrative review. Maturitas 76:296-302

103. Evans WJ, Morley JE, Argiles J et al (2008) Cachexia: a new definition. Clin Nutr 27:793-799

104. Cruz-Jentoft AJ, Baeyens JP, Bauer JM et al (2010) Sarcopenia: European consensus on definition and diagnosis: report of the European Working Group on Sarcopenia in Older People. Age Ageing 39:412-423

105. Rizzoli R, Stevenson JC, Bauer JM et al (2014) The role of dietary protein and vitamin $\mathrm{D}$ in maintaining musculoskeletal health in postmenopausal women: a consensus statement from the European Society for Clinical and Economic Aspects of Osteoporosis and Osteoarthritis (ESCEO). Maturitas 79:122-132

106. van den Berg P, van Haard PM, van den Bergh JP, Niesten DD, van der Elst M, Schweitzer DH (2014) First quantification of calcium intake from calcium-dense dairy products in Dutch fracture patients (the Delft cohort study). Nutrients 6:2404-2418

107. Dawson-Hughes B, Mithal A, Bonjour JP, Boonen S, Burckhardt P, Fuleihan GE, Josse RG, Lips P, Morales-Torres J, Yoshimura N (2010) IOF position statement: vitamin D recommendations for older adults. Osteoporos Int 21:1151-1154

108. Bischoff-Ferrari HA, Willett WC, Wong JB, Giovannucci E, Dietrich T, Dawson-Hughes B (2005) Fracture prevention with vitamin D supplementation: a meta-analysis of randomized controlled trials. JAMA 293:2257-2264

109. Bauer J, Biolo G, Cederholm T et al (2013) Evidence-based recommendations for optimal dietary protein intake in older people: a position paper from the PROT-AGE Study Group. J Am Med Dir Assoc 14:542-559

110. Schurch MA, Rizzoli R, Slosman D, Vadas L, Vergnaud P, Bonjour JP (1998) Protein supplements increase serum insulinlike growth factor-I levels and attenuate proximal femur bone loss in patients with recent hip fracture. A randomized, double-blind, placebo-controlled trial. Ann Intern Med 128:801-809

111. Milne AC, Potter J, Vivanti A, Avenell A (2009) Protein and energy supplementation in elderly people at risk from malnutrition. Cochrane Database Syst Rev CD003288

112. Avenell A, Handoll HH (2010) Nutritional supplementation for hip fracture aftercare in older people. Cochrane Database Syst Rev CD001880

113. Botella-Carretero JI, Iglesias B, Balsa JA, Arrieta F, Zamarron I, Vazquez C (2010) Perioperative oral nutritional supplements in normally or mildly undernourished geriatric patients submitted to surgery for hip fracture: a randomized clinical trial. Clin Nutr 29: 574-579

114. Devine A, Dick IM, Islam AF, Dhaliwal SS, Prince RL (2005) Protein consumption is an important predictor of lower limb bone mass in elderly women. Am J Clin Nutr 81:1423-1428

115. Meng X, Zhu K, Devine A, Kerr DA, Binns CW, Prince RL (2009) A 5-year cohort study of the effects of high protein intake on lean mass and BMC in elderly postmenopausal women. J Bone Miner Res 24:1827-1834

116. Dawson-Hughes B, Harris SS, Rasmussen H, Song L, Dallal GE (2004) Effect of dietary protein supplements on calcium excretion in healthy older men and women. J Clin Endocrinol Metab 89: 1169-1173

117. Mithal A, Bonjour JP, Boonen S et al (2013) Impact of nutrition on muscle mass, strength, and performance in older adults. Osteoporos Int 24:1555-1566

118. Kanis JA, McCloskey EV, Johansson H, Cooper C, Rizzoli R, Reginster JY, Scientific Advisory Board of the European Society for Clinical and Economic Aspects of Osteoporosis and Osteoarthritis, The Committee of Scientific Advisors of the International Osteoporosis Foundation (2013) European guidance for the diagnosis and management of osteoporosis in postmenopausal women. Osteoporos Int 24:23-57

119. Mitchell PJ (2013) Best practices in secondary fracture prevention: fracture liaison services. Curr Osteoporos Rep 11:52-60

120. International Osteoporosis Foundation (2015) Capture the fracture: break the worldwide fragility fracture cycle. http://www. capturethefracture.org/ Accessed 8 Jun 2015

121. Mitchell PJ, Ganda K, Seibel MJ (2015) Australian and New Zealand bone and mineral society position paper on secondary fracture prevention programs. Australian and New Zealand Bone and Mineral Society, Sydney

122. Osteoporosis Canada (2013) Make the FIRST break the LAST with fracture liaison services

123. Chandran M, Tan MZ, Cheen M, Tan SB, Leong M, Lau TC (2013) Secondary prevention of osteoporotic fractures-an "OPTIMAL" model of care from Singapore. Osteoporos Int 24:2809-2817 
124. Gittoes N, McLellan AR, Cooper A et al (2015) Effective secondary prevention of fragility fractures: clinical standards for fracture liaison services. National Osteoporosis Society, Camerton

125. National Bone Health Alliance (2014) Fracture Prevention Central. http://www.nbha.org/fpc Accessed 8 Jun 2015

126. Akesson K, Marsh D, Mitchell PJ, McLellan AR, Stenmark J, Pierroz DD, Kyer C, Cooper C, Group IOFFW (2013) Capture the fracture: a best practice framework and global campaign to break the fragility fracture cycle. Osteoporos Int 24:2135-2152

127. Misra M, Klibanski A (2014) Anorexia nervosa and bone. J Endocrinol 221:R163-R176

128. Targownik LE, Bernstein CN, Leslie WD (2014) Risk factors and management of osteoporosis in inflammatory bowel disease. Curr Opin Gastroenterol 30:168-174
129. Grace-Farfaglia P (2015) Bones of contention: bone mineral density recovery in celiac disease-a systematic review. Nutrients 7 : 3347-3369

130. Wilt TJ, Shaukat A, Shamliyan T, Taylor BC, MacDonald R, Tacklind J, Rutks I, Schwarzenberg SJ, Kane RL, Levitt M (2010) Lactose intolerance and health. Evid Rep Technol Assess $1-410$

131. Suchy FJ, Brannon PM, Carpenter TO et al (2010) NIH consensus development conference statement: lactose intolerance and health. NIH Consens State Sci Statements 27:1-27

132. National Osteoporosis Foundation (2014) The surgeon general's report: 10 years later. Washington DC 